\title{
Microbial EC50 Reference Control Result
}

National Cancer Institute

\section{Source}

National Cancer Institute. Microbial EC50 Reference Control Result. NCI Thesaurus. Code C139116.

A reference control sample response based on the concentration of a specific drug expected to produce 50 percent inhibition of the population growth or replication of a microbial organism. 